\title{
Mesenchymal chondroprogenitor cell origin and therapeutic potential
}

\author{
Janice O'Sullivan+, Sinéad D’Arcy ${ }^{\dagger}$, Frank P Barry, J Mary Murphy* and Cynthia M Coleman
}

\begin{abstract}
Mesenchymal progenitor cells, a multipotent adult stem cell population, have the ability to differentiate into cells of connective tissue lineages, including fat, cartilage, bone and muscle, and therefore generate a great deal of interest for their potential use in regenerative medicine. During development, endochondral bone is formed from a template of cartilage that transforms into bone; however, mature articular cartilage remains in the articulating joints, where its principal role is reducing friction and dispersing mechanical load. Articular cartilage is prone to damage from sports injuries or ageing, which regularly progresses to more serious joint disorders, such as osteoarthritis. Osteoarthritis is a degenerative joint disease characterized by the thinning and eventual wearing of articular cartilage, and affects millions of people worldwide. Due to low chondrocyte motility and proliferative rates, and complicated by the absence of blood vessels, cartilage has a limited ability to self-repair. Current pharmaceutical and surgical interventions fail to generate repair tissue with the mechanical and cellular properties of native host cartilage. The long-term success of cartilage repair will therefore depend on regenerative methodologies resulting in the restoration of articular cartilage that closely duplicates the native tissue. For cell-based therapies, the optimal cell source must be readily accessible with easily isolated, abundant cells capable of collagen type II and sulfated proteoglycan production in appropriate proportions. Although a cell source with these therapeutic properties remains elusive, mesenchymal chondroprogenitors retain their expansion capacity with the promise of reproducing the structural or biomechanical properties of healthy articular cartilage. As current knowledge regarding chondroprogenitors is relatively limited, this review will focus on their origin and therapeutic application.
\end{abstract}

\section{Introduction}

Osteoarthritis (OA) is a chronic disease of the joints characterized by progressive destruction of articular cartilage resulting in painful, limited joint movement. In the European Union over 39 million people exhibit symptoms of OA, a number anticipated to double in the next decade, creating an imperative for the timely development of effective treatments for the disease [1]. Current clinical therapies such as pharmaceutical interventions, bone marrow stimulation techniques or microfracture do not result in regeneration of healthy cartilage tissue [2,3], but focus on the short-term relief of OA symptoms. When pharmaceutical intervention fails, clinicians regularly revert to invasive and permanent solutions.

These authors contributed equally to the writing of this manuscript. *Correspondence: mary.murphy@remedi.ie

Regenerative Medicine Institute, National University of Ireland Galway, Galway City, County Galway, Ireland
The first widely accepted regenerative treatment for cartilage repair was autologous chondrocyte transplantation. Despite its initial therapeutic promise, chondrocyte transplantation has associated complications, such as donor site morbidity, repair cell de-differentiation with expansion in vitro and restricted cellular life span upon implantation [4]. Immature progenitor cells with the potential to develop into mature tissues in response to appropriate cues have therefore become a primary focus of cartilage repair strategies as an alternative to chondrocyte-based methods [5].

The application of chondroprogenitors, cells that are specifically pre-disposed to differentiate into mature chondrocytes, to repair articular lesions and subsequently inhibit the onset of $\mathrm{OA}$ is a current focus of research efforts. As the mature articular joint develops from embryonic mesodermal precursors that differentiate into chondroprogenitors and ultimately into mature adult chondrocytes or synoviocytes, it is hypothesized that progenitors retained in these adult articular tissues provide a potential reservoir of chondroprogenitors. 


\section{Development of the chondroprogenitor}

The development of the embryonic appendicular skeleton, whereby undifferentiated limb mesenchyme matures into a cartilaginous precursor and subsequently into bone, is dependent upon precursor exposure to specific combinations of morphogens and mechanical stimuli. Presumably a residual chondroprogenitor in the adult has been similarly primed and, when further stimulated, will respond by undergoing chondrogenic differentiation. Of critical importance during this developmental process are the transforming growth factor (TGF)- $\beta$, fibroblast growth factor (FGF), Wnt and Notch signaling pathways.

In embryonic limb development, FGF-4 stimulates Sonic hedgehog (Shh) expression in a positive feedback loop that coordinates proximal-distal and anterior-posterior patterning of the cartilaginous anlagen, as was historically demonstrated in an avian model [6]. Shh, in turn, initiates a cascade of stimulatory molecules such as those of the TGF- $\beta$ superfamily, thereby inducing mesenchymal differentiation into chondrocytes, as was originally demonstrated in murine limb mesenchyme [7]. Similarly, FGF-18 promotes cartilage formation in murine limb progenitor in vitro micromass cultures [8]. This effect is currently under clinical investigation for cartilage repair [9]. This phase I safety study assesses the ability of FGF-18 to stimulate chondrocyte development leading to the repair and regeneration of articular cartilage in patients undergoing knee replacement surgery. As FGF receptor isoform expression is highly regulated during each stage of embryonic human limb chondrogenesis [10], conserved FGF receptor expression patterns have been identified in embryonic chondrogenesis in vivo and progenitor cell differentiation in vitro, enabling a mechanism to compare tissue engineered cartilage with natural development [11].

Mesenchymal cell differentiation into chondrocytes, and the associated regulation of extracellular matrix (ECM) deposition, is minutely coordinated by paracrine factors. TGF- $\beta$ and bone morphogenetic protein (BMP) signaling, often through Sox9 as a transcriptional mediator, are responsible for initiating expression of cartilaginous ECM such as aggrecan, collagen types II and XI, fibronectin and tenascin in in vitro murine micromass cultures $[12,13]$. Opposing roles for the involvement of the mitogen-activated protein kinase signaling components ERK- 1 and $\mathrm{p} 38$ downstream of TGF- $\beta$ superfamily stimulation have been identified during in vitro chondrogenesis [14]; suppression of Erk-1/2 resulted in enhanced chondrogenesis whereas inhibition of p38 suppressed cartilage formation [15]. More specifically, inhibition of p38 significantly repressed formation of pre-chondrogenic nodules in vitro, sustained $\mathrm{N}$-cadherin expression and increased expression of fibronectin and $\alpha 5 \beta 1$ integrin, while ERK inhibition showed no effect on nodule formation, reduced expression of $\mathrm{N}$-cadherin and accelerated reduction of fibronectin and $\alpha 5 \beta 1$ integrin expression during late stages of chondrogenesis [15]. This delicate balance between signaling mechanisms is sustained in mature cartilage, ensuring maintenance of a healthy articular tissue [16].

Chondrogenic differentiation of adult human progenitor cells in vitro through TGF- $\beta 1$ is mediated intracellularly by both Smad3 and Wnt-associated $\beta$-catenin [17]. By increasing nodule formation, Wnts $5 \mathrm{a}$ and $5 \mathrm{~b}$ have been shown to promote early chondrogenesis in vitro [18] and play an important role in chondrocyte differentiation and proliferation in an in vivo mouse model by controlling expression of cell cycle regulators such as cyclin D1 and p130 [19]. However, expression of Wnts 14, 7a and 1 have been demonstrated to inhibit the chondrocyte maturation in in vivo chick models and in in vitro micromass cultures [20].

A distinct population of murine embryonic precursors located at the prospective joint will develop into adult articular cartilage and synovial tissues, in contrast to the remaining cartilaginous template that ossifies to form the appendicular skeleton [21]. As the embryonic development of articular cartilage proceeds from the preliminary cartilaginous template to an articulated joint with striated cartilage and underlying subchondral bone, Notch signaling plays a fundamental role as demonstrated in vivo with an avian model [22]. Notch signaling via JAG1 is required to initiate chondrogenesis in adult human progenitor cells in vitro [23]; however, maintained Notch signaling in adult human progenitor cell micromass cultures suppresses differentiation by inhibiting Sox9 binding of the collagen type II promoter [24], indicating that temporal regulation of Notch signaling is paramount to proper development.

Recent advances indicate a strong association between hypoxia-inducible factors (HIFs) in chondrogenesis and the development of OA. While HIF-1 $\alpha$ stimulates chondrogenic differentiation, HIF- $2 \alpha$ is involved in endochondral ossification and cartilage degradation. Amarilio and colleagues [25] inactivated HIF-1 $\alpha$ in mouse limb bud mesenchyme, resulting in abnormal joint and cartilage formation in vivo, indicating HIF- $1 \alpha$ regulates the differentiation of pre-chondrocytes. Further in vitro studies demonstrated reduced cartilage formation in $H I F-1 \alpha$-depleted micromass cultures and reduced expression of key chondrogenic markers Sox9, Sox6, aggrecan and collagen type II [25]. In vivo functional studies by Yang and colleagues [26] demonstrated that HIF- $2 \alpha$ is a critical transcription factor that catabolically regulates cartilage degradation through matrix metalloproteinase and ADAMTS (a disintegrin and metalloproteinase with thrombospondin motifs) expression. 
The delicate balance of paracrine factors discussed above, as well as several other factors not reviewed here, results in the differentiation of an embryonic mesenchymal progenitor cell into a mature articular chondrocyte. Presumably chondroprogenitors residing in the adult have also been primed by these signals and will therefore respond similarly by undergoing chondrogenic differentiation when further stimulated, making them an attractive cell source for the regeneration of cartilage. The successful identification of a pool of chondroprogenitors in vivo, followed by their isolation and in vitro expansion, is therefore a pre-requisite to their clinical application.

\section{Progenitor cell tissue distribution}

Adult progenitor cells have been described in vivo and in vitro as mobile cells with both differentiation and selfrenewal potential that reside in a niche adjacent to mature, differentiated cells [27]. Progenitors have been successfully retrieved from several sources, including adipose, synovium, synovial fluid, perichondrium and bone marrow [28-31] (summarized in Table 1). Depending on the tissue source from which they are isolated, progenitors harbor distinct differentiation potential and occur at variable frequencies.

Efforts by Friedenstein and colleagues [31] and Pittenger and colleagues [32] unequivocally demonstrated the presence and potential of bone marrow-derived mesenchymal stem cells (MSCs) with the innate ability to differentiate into multiple mesenchymal lineages in vitro. Despite their rare occurrence $(0.001$ to $0.01 \%$ of cells in the stromal compartment [32]), bone marrow-derived MSCs may be efficiently isolated and expanded in culture without associated donor site morbidity.

Bone marrow-derived MSCs are isolated nonselectively by exposing the mononuclear cell aspiration to tissue culture plastic. Adherent progenitors, termed colony forming unit-fibroblasts (CFU-Fs), initiate the generation of a clonal population of CD105-positive, CD73-positive, CD90-positive and CD44-positive cells that are then expanded in monolayer [33]. Clonal analysis of bone marrow-derived MSCs describes 20 to $50 \%$ of the total population of cells to be truly tri-potent, but most importantly has identified a subpopulation of MSCs that retains only chondrogenic potential, or chondroprogenitors [34]. As the resultant population of MSCs is heterogeneous, efforts continue to identify and isolate a homogenous chondroprogenitor cell population from marrow that would more efficaciously repair diseased cartilage.

Similar to those in marrow, adult periosteal-derived multipotent progenitors are tri-potent [35]. Regardless of donor age, periosteal progenitors are clonogenic and have significant in vitro expansion potential [36] with continued positive expression of traditional bone marrow-derived progenitor cell markers such as CD105, CD166, CD13, CD73 and D7-FIB [28]. Most importantly, identification of specifically chondro- and osteogenic precursors within the periosteum has been identified, making this tissue an attractive tissue source for chondroprogenitor isolation [37].

The mature synovial membrane is composed of a fibrous external layer and an inner secretory layer that produces synovial fluid. Synovial tissue-derived multilineage progenitors may have the greatest overall therapeutic potential to regenerate damaged cartilage due to their impressive capacity for proliferation and their superior chondrogenic differentiation potential [38]. Interestingly, during the early stages of OA there is an increase in progenitor cell numbers in synovial fluid, presumably as a result of synovial membrane degradation leading to their release into the synovial fluid [39]. Synovial membrane derived mesodermal progenitors uniquely are not depleted in number or potential with donor age [38], making them an attractive cell source for autologous therapy.

Like synovium and bone marrow, infrapatellar fat pad contains a readily abundant source of CD105-positive, CD44-positive and CD166-positive progenitor cells with the potential to differentiate into mesodermal lineages. CD271 expression, a putative marker of the in vivo progenitor cell [40], is highly expressed in adipose progenitors and is uniquely maintained with proliferation, indicating retention of their progenitor capacity upon expansion [29].

Although healthy mature cartilage is primarily composed of mature chondrocytes, progenitor cells with chondrogenic capacity have been isolated from the superficial zone of articular cartilage [41]. Additionally, chondroprogenitors have been identified in arthritic cartilage after their migration from the bone marrow through breaks in the tidemark and into the diseased cartilage [42]. With two potential sources of progenitor cells, one in the healthy superficial zone and another generated as a repair response to disease, the development of technologies to harness and retain their potential may offer novel regenerative therapeutics.

Progenitor cells have also been identified in tendon, specifically in an ECM-rich niche. The tendon-derived stem/progenitor cells (TSPCs) are clonogenic with a higher rate of proliferation compared to bone marrowderived MSCs. TSPCs are multipotent with an enhanced potential for osteo- and adipogenic differentiation compared to bone marrow-derived progenitors. With diminished chondrogenic potential and proficient tenogenic potential, TSPCs are perhaps best suited for tendon repair applications [43].

Comparison of progenitors derived from adult bone marrow, synovium, periosteum and adipose has 
Table 1. Overview of progenitor cell tissue sources

\begin{tabular}{|c|c|c|c|}
\hline Source & Advantages & Disadvantages & Cell surface phenotype \\
\hline $\begin{array}{l}\text { Bone marrow } \\
{[31-33,44]}\end{array}$ & $\begin{array}{l}\text { Twenty to fifty percent of cells are tri-potent } \\
\text { Contains specifically chondroprogenitor } \\
\text { subpopulations } \\
\text { High expansion potential }\end{array}$ & $\begin{array}{l}\text { Heterogeneous population of cells } \\
\text { Contains fewer CFU-Fs compared to other } \\
\text { cell sources } \\
\text { Invasive procedure to harvest }\end{array}$ & $\begin{array}{l}\mathrm{CD}^{2} 5^{+}, \mathrm{CD}^{+} 3^{+}, \mathrm{CD}^{\circ} 4^{+}, \mathrm{CD}^{+} 0^{+}, \\
\mathrm{CD} 271^{+}, \mathrm{CD} 14^{+}, \mathrm{CD} 13^{+}, \mathrm{CD} 166^{+}, \\
\text {CD34; }{ }^{-} \mathrm{CD} 45^{\circ}, \mathrm{CD} 117^{-}, \mathrm{CD} 31^{-} \\
\text {VEGFR-2 }\end{array}$ \\
\hline $\begin{array}{l}\text { Synovium and } \\
\text { synovial fluid } \\
{[38,44]}\end{array}$ & $\begin{array}{l}\text { High expansion potential regardless of donor age } \\
\text { Superior chondrogenic differentiation potential } \\
\text { No reduction in cell number or potential with } \\
\text { donor age } \\
\text { Increase in progenitor cell numbers in early OA }\end{array}$ & Heterogeneous population of cells & $\begin{array}{l}\mathrm{CD} 105^{+}, \mathrm{CD}^{+} 3^{+}, \mathrm{CD}_{4} 4^{+}, \mathrm{CD}^{+} 0^{+} \\
\mathrm{CD} 271^{+}, \mathrm{CD} 13^{+}, \mathrm{CD} 166^{+}, \mathrm{CD} 10^{-} \\
\mathrm{CD} 34, \mathrm{CD} 45^{-}, \mathrm{CD} 117^{-}, \mathrm{CD} 31^{-} \\
\text {VEGFR-2- }\end{array}$ \\
\hline $\begin{array}{l}\text { Infrapatellar fat } \\
\text { pad }[40,44]\end{array}$ & $\begin{array}{l}\text { Abundant source of progenitor cells } \\
\text { Superior retention of differentiation potential } \\
\text { upon expansion }\end{array}$ & $\begin{array}{l}\text { Comparable differentiation capacity to other } \\
\text { tissue sources } \\
\text { Relatively early senescence }\end{array}$ & $\begin{array}{l}\mathrm{CD} 105^{+}, \mathrm{CD}^{+} 3^{+}, \mathrm{CD} 44^{+}, \mathrm{CD} 166^{+}, \\
\mathrm{CD} 271^{+}, \mathrm{CD} 13^{+}, \mathrm{CD} 90^{+}, \mathrm{CD} 34, \\
\mathrm{CD} 45^{\circ}, \mathrm{CD} 31^{-}, \mathrm{VEGF}^{-}{ }^{-}\end{array}$ \\
\hline Tendon [43] & $\begin{array}{l}\text { Tri-potent cell population, positive chondrogenic } \\
\text { differentiation, however, excelling in osteo- and } \\
\text { adipogenic potential } \\
\text { Significant expansion potential }\end{array}$ & $\begin{array}{l}\text { Low availability of autologous tendon tissue } \\
\text { Minimal chondrogenic capacity }\end{array}$ & 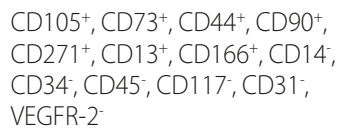 \\
\hline Periosteum [28] & $\begin{array}{l}\text { Progenitors are multi-potent } \\
\text { Significant in vitro expansion potential and } \\
\text { clonogenicity despite donor age }\end{array}$ & $\begin{array}{l}\text { Consists of a heterogeneous population of } \\
\text { cells } \\
\text { Invasive harvest procedure }\end{array}$ & 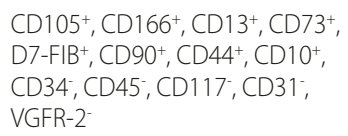 \\
\hline
\end{tabular}

Depending on the adult source tissue, isolated progenitor cells vary in cell surface phenotype, expansion and differentiation potential. Before clinical application, careful consideration of the adult tissue source and capability of the derived reparative cell is therefore warranted. CFU-F, colony forming unit-fibroblast; OA, osteoarthritis.

demonstrated distinct differences between these cell types $[29,30]$. Upon initial isolation of progenitor cells, there are significantly fewer CFU-Fs in bone marrowderived cells compared to progenitors from adipose, periosteum or synovium. Synovial fluid and bone marrow-derived progenitor cells share a similar chondrogenic or osteogenic potential [44]; however, synovial membrane-derived cells in particular retain significant potential for chondrogenesis [38]. Together, these adult tissue sources offer an opportunity to specifically isolate progenitors that when clonally analyzed are predisposed to differentiate into chondrocytes, thereby offering a source of highly efficacious repair cells. Figure 1 depicts some possible sources of chondroprogenitors. The increased potential of synovium-derived progenitors may be associated with the proximity of the niche they reside in to articular cartilage. A common embryonic genesis for articular cartilage and synovial tissue may also be a factor [21]. Migration of progenitor-like cells from marrow to OA cartilage has been suggested but has not as yet been identified in the healthy joint and the presence of marrow-derived mesenchymal-like progenitors in rheumatoid arthritic pannus highlights an additional route for migration of marrow-derived chondroprogenitors [45]. However, identification of the optimal chondroprogenitor awaits a direct intra-donor comparison of cells isolated from the various sources.

\section{Clinical considerations and therapeutic applications}

Articular chondrocytes, when explanted and expanded in vitro, lose their chondrocytic phenotype as indicated by morphometric changes and elimination of collagen type II deposition [46]. The re-differentiation of these cells in vitro regenerates their articular phenotype while the differentiation of a progenitor cell in vitro results in the generation of a transient, pre-hypertrophic chondrocyte, similar to the chondrocyte phenotype in the developing embryonic skeleton [47], highlighting the inherent difference between progenitors and native chondrocytes [48]. Essential to the functional formation of neocartilage through the implementation of progenitors is the acknowledgement of these evident differences in the phenotypic state, and our ability to develop methods to overcome the present gaps. It is crucial that research focuses on not only the signaling events that are known to support chondrogenic differentiation in the embryo but also on the molecular events that fail to initiate in progenitor cell differentiation.

Bone marrow-derived MSCs have been directly injected [49] or combined with a scaffold and implanted [50] into the intra-articular space in vivo in an effort to assess their potential for efficacious repair of damaged cartilage tissue or diseased joints. These results have proven to be ambiguous and unsatisfactory as a result of low viability and retention of the cells [49]. Due to inconsistency in results and association with hypertrophy and ossification, there are very few human clinical trials investigating heterogeneous bone marrow-derived MSCs as a therapeutic for cartilage repair.

The ongoing Chondrogen clinical trial is currently investigating the application of bone marrow-derived MSCs to treat meniscal damage and thereby delay the onset of OA. Conducted by Osiris Therapeutics, 


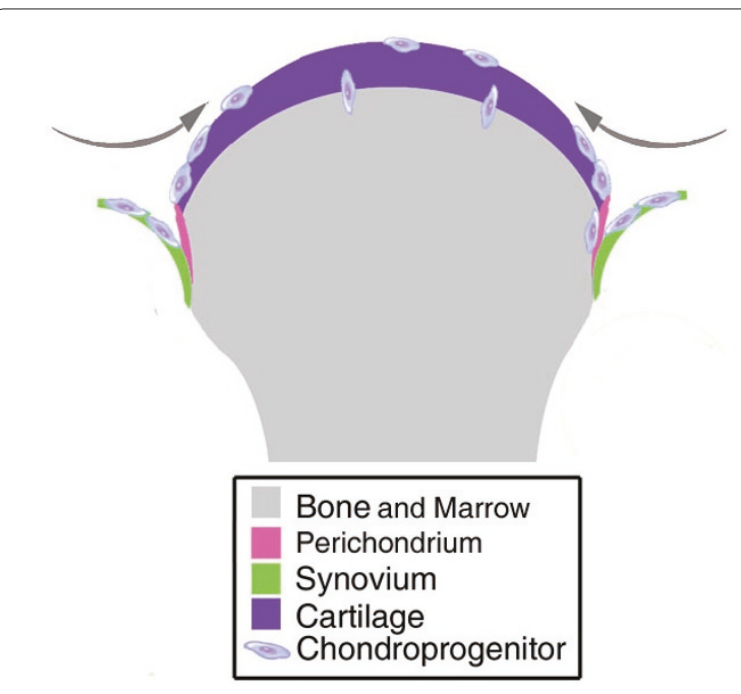

Figure 1. Potential sources for isolation of chondroprogenitors. Progenitor cells with chondrogenic potential have been isolated from bone marrow, synovium, perichondrium and cartilage itself. The relative ability of these cells to contribute to normal cartilage homeostasis or repair of diseased tissue may be related to their niche or developmental origin.

preliminary reports have claimed a statistically and clinically significant improvement in pain experienced by patients post-injury with application of MSCs [51]. The application of Chondrogen was well tolerated by recipients and superior to currently available, comparable products on the market. With advances in chondroprogenitor cell isolation and culture techniques, products such as this will be improved upon by replacing large numbers of perhaps minimally efficacious heterogeneous MSCs with low numbers of highly efficacious chondroprogenitors.

To treat chondral defects, Advanced Technologies and Regenerative Medicine is currently investigating a cartilage autograft implantation system where autologous healthy cartilage is harvested from non-weight bearing regions, minced and re-distributed on a scaffold for implantation. Initial results have been promising, supporting a phase III clinical investigation [52]. If left untreated, lesions such as these regularly result in the onset of OA. It is possible that the reparative cell responsible for the generation of neocartilage in this trial is indeed the re-implanted chondroprogenitor residing on the superficial surface of the harvested cartilage tissue. By identifying the reparative cell in this application, a less invasive methodology for reparative cell isolation could be developed, thereby greatly reducing donor site morbidity as well as enhancing the efficacy of the therapy.

TissueGene, Inc. is currently investigating the safety of intra-articular application of chondrocytes modified virally to overexpress TGF- $\beta 1$ as a potential treatment for arthritic lesions [53]. Although preliminary results are not yet available, re-creation of the embryonic environment by supplementing cells with TGF- $\beta 1$ may significantly contribute to cartilage repair over the application of chondrocytes alone, especially after their in vitro expansion and consequential de-differentiation.

The benefits and disadvantages of allogeneic versus autologous cell-based clinical therapies continue to be debated. In a clinical study supported by the National Institutes of Health, this specific question will be addressed by comparing autologous and allogenic MSC therapies in the setting of heart failure [54]. Recent phase I clinical administration of allogenic MSC therapies to myocardial infarct patients validated the safety of allogenic cells [54] and autologous cells [55]. However, their long-term survival, engraftment and mechanism of action remain unclear [56].

\section{Conclusion}

Several million people worldwide suffer from OA, a chronic, debilitating disorder of the articulating joints. As current clinical interventions do not stimulate the generation of a mechanically sound reparative tissue, but focus on the short-term relief of OA symptoms, the field now looks to progenitor cell-based therapies as our future; specifically, progenitor cells primed for chondrogenic differentiation. Chondroprogenitors residing in the adult have hypothetically been primed for chondrogenic differentiation with Wnts, FGFs and TGF- $\beta$ superfamily members; just as embryonic limb mesenchyme is influenced, and, when stimulated, will differentiate into high quality articular cartilage. Recent chondrocyte- or MSC-based clinical trials have failed to meet their primary endpoints, often due to our minimal knowledge of their mechanism of action and fate following delivery. Nevertheless, the clinical application of chondroprogenitors for cartilage regeneration may have a bright future with a greater understanding of their embryonic development and the identification of a reliable tissue source. The clinical application of a homologous chondroprogenitor population will eliminate the need for heterogeneous cell therapies [56] and result in an efficacious, minimally invasive approach to articular cartilage repair.

\section{Abbreviations}

CFU-F, colony forming unit-fibroblast; ECM, extracellular matrix; FGF, fibroblast growth factor; HIF, hypoxia-inducible factor; MSC, mesenchymal stem cell; OA, osteoarthritis; Shh, Sonic hedgehog; TGF, transforming growth factor; TSPC, tendon-derived stem/progenitor cell.

\section{Competing interests}

The authors declare that they have no competing interests.

\section{Authors' contributions}

JOS, SD and CMC were primarily involved in drafting the review. FM and JMM contributed to drafting the manuscript as well as providing critical review of content. All authors read and approved the final manuscript.

Published: 18 February 2011 


\section{References}

1. Davis MA: Epidemiology of osteoarthritis. Clin Geriatr Med 1988, 4:241-255.

2. Qvist P, Bay-Jensen AC, Christiansen C, Dam EB, Pastoureau P, Karsdal MA: The disease modifying osteoarthritis drug (DMOAD): Is it in the horizon? Pharmacol Res 2008, 58:1-7.

3. Mithoefer K, MCAdams T, Williams RJ, Kreuz PC, Mandelbaum BR: Clinical efficacy of the microfracture technique for articular cartilage repair in the knee: an evidence-based systematic analysis. Am J Sports Med 2009 37:2053-2063

4. Brittberg $M$, Peterson $L$ : Articular cartilage engineering with autologous chondrocyte transplantation: a review of recent developments. J Bone Joint Surg 2003, 85:109.

5. Curtin C, Curtin W, Scarpa T, Dockery P, Paoletti S, O'Brien T, Barry F, Murphy $\mathrm{JM}$ : Targeted delivery of stem cells to osteoarthritic cartilage using lactose-modified chitosan. Orthopaedic Res Soc Trans 2009, 34:Paper 502.

6. Niswander L, Jeffrey S, Martin GR, Tickle C: A positive feedback loop coordinates growth and patterning in the vertebrate limb. Nature 1994 371:609-612.

7. Karamboulas K, Dranse HJ, Underhill TM: Regulation of BMP-dependent chondrogenesis in early limb mesenchyme by TGFbeta signals. J Cell SCi 2010, 123:2068-2076

8. Davidson D, Blanc A, Filion D, Wang H, Plut P, Pfeffer G, Buschmann MD, Henderson JE: Fibroblast growth factor (FGF) 18 signals through FGF receptor 3 to promote chondrogenesis. J Biol Chem 2005, 280:20509-20515.

9. ClinicalTrials.gov: Study of AS902330 (rhFGF-18) Administered Intraarticularly in Patients With Knee Primary Osteoarthritis Who Are Candidates for Total Knee Replacement [http://www.clinicaltrials.gov/ct2/ show/NCT0091 1469?term=cartilage+AND+cell\&rank=10]

10. Delezoide AL, Benoist-Lasselin C, Legeai-Mallet L, Le Merrer M, Munnich A Vekemans M, Bonaventure J: Spatio-temporal expression of FGFR 1, 2 and 3 genes during human embryo-fetal ossification. Mech Dev 1998, 77:19-30.

11. Hellingman CA, Koevoet W, Kops N, Farrell E, Jahr H, Liu W, de Jong RJ, Frenz $D A$, van Osch GJ: Fibroblast growth factor receptors in in vitro and in vivo chondrogenesis: relating tissue engineering using adult mesenchymal stem cells to embryonic development. Tissue Eng Part A 2010, 16:545-556.

12. Hatakeyama Y, Tuan RS, Shum L: Distinct functions of BMP4 and GDF5 in the regulation of chondrogenesis. J Cell Biochem 2004, 91:1204-1217.

13. Chimal-Monroy J, Diaz de Leon L: Expression of N-cadherin, N-CAM fibronectin and tenascin is stimulated by TGF-beta1, beta2, beta3 and beta5 during the formation of precartilage condensations. Int J Dev Biol 1999, 43:59-67.

14. Alessi DR, Cuenda A, Cohen P, Dudley DT, Saltiel AR: PD 098059 is a specific inhibitor of the activation of mitogen-activated protein kinase kinase in vitro and in vivo. J Biol Chem 1995, 270:27489-27494.

15. Oh CD, Chang SH, Yoon YM, Lee SJ, Lee YS, Kang SS, Chun JS: Opposing role of mitogen-activated protein kinase subtypes, erk-1/2 and p38, in the regulation of chondrogenesis of mesenchymes. J Biol Chem 2000, 275:5613-5619.

16. Beier F, Loeser RF: Biology and pathology of Rho GTPase, PI-3 kinase-Akt, and MAP kinase signaling pathways in chondrocytes. $J$ Cell Biochem 2010, 110:573-580.

17. Jian H, Shen X, Liu I, Semenov M, He X, Wang XF: Smad3-dependent nuclear translocation of beta-catenin is required for TGF-beta1-induced proliferation of bone marrow-derived adult human mesenchymal stem cells. Genes Dev 2006, 20:666-674.

18. Church V, Nohno T, Linker C, Marcelle C, Francis-West P: Wnt regulation of chondrocyte differentiation. J Cell Sci 2002, 115:4809-4818.

19. Yang $Y$, Topol L, Lee $H, W u$ J: Wnt5a and Wnt5b exhibit distinct activities in coordinating chondrocyte proliferation and differentiation. Development 2003, 130:1003-1015.

20. Chun JS, Oh H, Yang S, Park M: Wnt signaling in cartilage development and degeneration. BMB Rep 2008, 41:485-494.

21. Koyama E, Shibukawa Y, Nagayama M, Sugito H, Young B, Yuasa T, Okabe T, Ochiai T, Kamiya N, Rountree RB, Kingsley DM, Iwamoto M, EnomotoIwamoto M, Pacifici M: A distinct cohort of progenitor cells participates in synovial joint and articular cartilage formation during mouse limb skeletogenesis. Dev Bio/ 2008, 316:62-73.

22. Williams R, Nelson L, Dowthwaite GP, Evans DJ, Archer CW: Notch receptor and Notch ligand expression in developing avian cartilage. J Anat 2009, 215:159-169.

23. Oldershaw RA, Tew SR, Russell AM, Meade K, Hawkins R, McKay TR, Brennan
$\mathrm{KR}$, Hardingham TE: Notch signaling through Jagged-1 is necessary to initiate chondrogenesis in human bone marrow stromal cells but must be switched off to complete chondrogenesis. Stem Cells 2008, 26:666-674.

24. Grogan SP, Olee T, Hiraoka K, Lotz MK: Repression of chondrogenesis through binding of notch signaling proteins HES-1 and HEY-1 to N-box domains in the COL2A1 enhancer site. Arthritis Rheum 2008, 58:2754-2763.

25. Amarilio R, Viukov SV, Sharir A, Eshkar-Oren I, Johnson RS, Zelzer E: HIF1alpha regulation of Sox9 is necessary to maintain differentiation of hypoxic prechondrogenic cells during early skeletogenesis. Development 2007, 134:3917-3928.

26. Yang S, Kim J, Ryu JH, Oh H, Chun CH, Kim BJ, Min BH, Chun JS: Hypoxiainducible factor-2alpha is a catabolic regulator of osteoarthritic cartilage destruction. Nat Med 2010, 16:687-693.

27. Barry F, Boynton RE, Liu B, Murphy JM: Chondrogenic differentiation of mesenchymal stem cells from bone marrow: differentiation-dependent gene expression of matrix components. Exp Cell Res 2001, 268:189-200.

28. Arai F, Ohneda O, Miyamoto T, Zhang X, Suda T: Mesenchymal stem cells in perichondrium express activated leukocyte cell adhesion molecule and participate in bone marrow formation. J Exp Med 2002, 195:1549.

29. English A, Jones E, Corscadden D, Henshaw K, Chapman T, Emery P, McGonagle D: A comparative assessment of cartilage and joint fat pad as a potential source of cells for autologous therapy development in knee osteoarthritis. Rheumatology 2007, 46:1676

30. De Ugarte D, Morizono K, Elbarbary A, Alfonso Z, Zuk P, Zhu M, Dragoo J, Ashjian P, Thomas B, Benhaim P: Comparison of multi-lineage cells from human adipose tissue and bone marrow. Cells Tissues Organs 2000, 174:101-109.

31. Friedenstein A, Piatetzky-Shapiro I, Petrakova K: Osteogenesis in transplants of bone marrow cells. Development 1966, 16:381.

32. Pittenger M, Mackay A, Beck S, Jaiswal R, Douglas R, Mosca J, Moorman M, Simonetti D, Craig S, Marshak D: Multilineage potential of adult human mesenchymal stem cells. Science 1999, 284:143.

33. Dominici M, Le Blanc K, Mueller I, Slaper-Cortenbach I, Marini F, Krause D, Deans R, Keating A, Prockop D, Horwitz E: Minimal criteria for defining multipotent mesenchymal stromal cells. The International Society for Cellular Therapy position statement. Cytotherapy 2006, 8:315-317.

34. Russell KC, Phinney DG, Lacey MR, Barrilleaux BL, Meyertholen KE, O'Connor $\mathrm{KC}:$ In vitro high-capacity assay to quantify the clonal heterogeneity in trilineage potential of mesenchymal stem cells reveals a complex hierarchy of lineage commitment. Stem Cells 2010, 28:788-798.

35. De Bari C, Dell'Accio F, Luyten F: Human periosteum-derived cells maintain phenotypic stability and chondrogenic potential throughout expansion regardless of donor age. Arthritis Rheum 2001, 44:85-95.

36. De Bari C, Dell'Accio F, Vanlauwe J, Eyckmans J, Khan I, Archer C, Jones E, McGonagle D, Mitsiadis T, Pitzalis C: Mesenchymal multipotency of adult human periosteal cells demonstrated by single-cell lineage analysis. Arthritis Rheum 2006, 54:1209-1221.

37. Nakase T, Nakahara H, Iwasaki M, Kimura T, Kimata K, Watanabe K, Caplan A, Ono K: Clonal analysis for developmental potential of chick periosteumderived cells: agar gel culture system. Biochem Biophys Res Commun 1993, 195:1422-1428.

38. De Bari C, Dell'Accio F, Tylzanowski P, Luyten F: Multipotent mesenchymal stem cells from adult human synovial membrane. Arthritis Rheum 2001, 44:1928-1942.

39. Jones E, Crawford A, English A, Henshaw K, Mundy J, Corscadden D, Chapman T, Emery P, Hatton P, McGonagle D: Synovial fluid mesenchymal stem cells in health and early osteoarthritis: detection and functional evaluation at the single-cell level. Arthritis Rheum 2008, 58:1731-1740.

40. Jones EA, Kinsey SE, English A, Jones RA, Straszynski L, Meredith DM Markham AF, Jack A, Emery P, McGonagle D: Isolation and characterization of bone marrow multipotential mesenchymal progenitor cells. Arthritis Rheum 2002, 46:3349-3360.

41. Dowthwaite G, Bishop J, Redman S, Khan I, Rooney P, Evans D, Haughton L, Bayram Z, Boyer S, Thomson B: The surface of articular cartilage contains a progenitor cell population. J Cell Sci 2004, 117:889.

42. Koelling S, Kruegel J, Irmer M, Path J, Sadowski B, Miro X, Miosge N: Migratory chondrogenic progenitor cells from repair tissue during the later stages of human osteoarthritis. Cell stem cell 2009, 4:324-335.

43. Bi Y, Ehirchiou D, Kilts TM, Inkson CA, Embree MC, Sonoyama W, Li L, Leet Al, Seo BM, Zhang L, Shi S, Young MF: Identification of tendon stem/progenitor cells and the role of the extracellular matrix in their niche. Nat Med 2007 
13:1219-1227.

44. Peng L, Jia Z, Yin X, Zhang X, Liu Y, Chen P, Ma K, Zhou C: Comparative analysis of mesenchymal stem cells from bone marrow, cartilage, and adipose tissue. Stem Cells Dev 2008, 17:761-773.

45. Li X, Makarov SS: An essential role of NF-kappaB in the "tumor-like" phenotype of arthritic synoviocytes. Proc Natl Acad Sci U S A 2006, 103:17432-17437.

46. Wakitani S, Kawaguchi A, Tokuhara Y, Takaoka K: Present status of and future direction for articular cartilage repair. J Bone Miner Metab 2008, 26:115-122.

47. Winter A, Breit S, Parsch D, Benz K, Steck E, Hauner H, Weber R, Ewerbeck V, Richter W: Cartilage-like gene expression in differentiated human stem cell spheroids: a comparison of bone marrow-derived and adipose tissuederived stromal cells. Arthritis Rheum 2003, 48:418-429.

48. Huang A, Yeger-McKeever M, Stein A, Mauck R: Tensile properties of engineered cartilage formed from chondrocyte-and MSC-laden hydrogels. Osteoarthritis Cartilage 2008, 16:1074-1082.

49. Murphy J, Fink D, Hunziker E, Barry F: Stem cell therapy in a caprine model of osteoarthritis. Arthritis Rheum 2003, 48:3464-3474.

50. Liu Y, Shu X, Prestwich G: Osteochondral defect repair with autologous bone marrow-derived mesenchymal stem cells in an injectable, in situ, cross-linked synthetic extracellular matrix. Tissue Eng 2006, 12:3405-3416.

51. ClinicalTrials.gov: A Phase I/II Study of Chondrogen Delivered by IntraArticular Injection Following Meniscectomy [http://www.clinicaltrials.gov/ ct2/show/NCT00225095?term=chondrogen\&rank=2]
52. ClinicalTrials.gov: Cartilage Autograft Implantation System (CAIS) for the Repair of Knee Cartilage Through Cartilage Regeneration [http://www. clinicaltrials.gov/ct2/show/NCT00881023?term=CAIS\&rank=1]

53. ClinicalTrials.gov:Safety Study of TissueGene-C in Degenerative Joint Disease of the Knee (TGC-03-01) [http://www.clinicaltrials.gov/ct2/show/NC T00599248?term=TissueGene\&rank=1]

54. Hare JM, Traverse JH, Henry TD, Dib N, Strumpf RK, Schulman SP, Gerstenblith G, DeMaria AN, Denktas AE, Gammon RS, Hermiller JB Jr, Reisman MA, Schaer GL, Sherman W: A randomized, double-blind, placebo-controlled, doseescalation study of intravenous adult human mesenchymal stem cells (prochymal) after acute myocardial infarction. J Am Coll Cardiol 2009, 54:2277-2286

55. Lunde K, Solheim S, Aakhus S, Arnesen H, Abdelnoor M, Forfang K: Autologous stem cell transplantation in acute myocardial infarction: The ASTAMI randomized controlled trial. Intracoronary transplantation of autologous mononuclear bone marrow cells, study design and safety aspects. Scand Cardiovasc J 2005, 39:150-158.

56. Ankrum J, Karp JM: Mesenchymal stem cell therapy: Two steps forward, one step back. Trends Mol Med 2010, 16:203-209.

doi:10.1186/scrt49

Cite this article as: O'Sullivan J, et al:: Mesenchymal chondroprogenitor cell origin and therapeutic potential. Stem Cell Research \& Therapy 2011, 2:8. 